\title{
HUBUNGAN FREKUENSI HEMODIALISIS DENGAN TINGKAT STRES PADA PASIEN GAGAL GINJAL KRONIK YANG MENJALANI HEMODIALISIS DI RUMAH SAKIT ROYAL PRIMA MEDAN TAHUN 2019
}

\author{
Novi Oktaviana, Juwita Verawati, Donna Putra, Helpin, Onangego \\ Program Studi S1-Keperawatan Fakultas Keperawatan Dan Kebidanan Universitas Prima Indonesia \\ novi.oktaviana10@gmail.com
}

\begin{abstract}
Kidney failure is caused by decreased kidney function so that it cannot filter out the body's electrolyte discharge. The aim of the study was to find out whether there was a relationship between the frequency of hemodialysis and the level of stress in patients with chronic kidney failure who underwent hemodialysis at Royal Prima Medan Hospital in 2019. The research design used by the researcher was a cros sectional method in which the dependent and independent variables were examined simultaneously. The results showed that there was a significant relationship between the frequency of hemodialysis to stress levels in patients with chronic renal failure, almost all respondents often underwent hemodialysis at Royal Prima Hospital in Medan, out of a total of 70 respondents, almost all respondents had moderate stress levels and there was a significant relationship between $H D$ frequency with stress levels in CRF patients in the Hemodialysis installation with a $p$ value of $0.002<0.05$. The results of this study are expected to be able to add insight and knowledge about $C R F$, and are expected to continue this research in deeper contexts and broader variables.
\end{abstract}

Keywords: Frequency, Hemodialysis, Stress Level

\section{PENDAHULUAN}

Ginjal merupakan organ yang berbentuk seperti kacang, berwarna merah tua, terletak dikedua sisi kolumna vertebralis. Ginjal berfungsi sebagai pengatur volume dan komposisi kimia darah dan lingkungan dalam tubuh dengan mengekskresikan zat terlarut dan air secara selektif. Ginjal juga berfungsi sebagai filtrasi plasma darah melalui glomerulus diikuti dengan reabsorbsi sejumlah zat terlalut dan air dalam jumlah yang tepat disepanjang tubulus ginjal (Suryanto,2009).

Menurut hasil penelitian Global Burden of Disease tahun 2010, Penyakit Ginjal Kronis merupakan penyebab kematian peringkat ke 27 di dunia tahun 1990 dan meningkat menjadi urutan ke 18 pada tahun 2010, Lebih dari 2 juta penduduk di dunia mendapatkan perawatan dengan dialisis atau transplantasi ginjal dan hanya sekitar $10 \%$ yang benar-benar mengalami perawatan tersebut. Sepuluh persen penduduk di dunia mengalami Penyakit Ginjal Kronis dan jutaan meninggal setiap tahun karena tidak mempunyai akses untuk pengobatan.

Berdasarkan Indonesian Renal Registry (IRR) tahun 2017, jumlah pasien baru yang menjalani pertama kali hemodialisis pada tahun 2017 sebanyak 30.831 sedangkan pasien yang aktif adalah seluruh pasien baik pasien tahun 2017 maupun pasien lama dari tahun sebelumnya yang masih menjalani hemodialis sebanyak 77.892 .

Menurut data dari Dinas Kesehatan Provinsi Sumatera Utara pada tahun 2014, penderita gagal ginjal kronik berjumlah 2608 jiwa dengan jumlah penderita terbanyak pada usia diatas 55 tahun.

Hasil Riskesdas (2018), jumlah penderita gagal ginjal kronis meningkat seiring dengan bertambahnya umur, meningkat tajam pada kelompok umur 35-44 tahun $(0,33 \%)$, diikuti umur 45-54 tahun $(0,56 \%)$, dan umur 5564 tahun $(0,72 \%)$, tertinggi pada kelompok umur 65-74 tahun $(0,82 \%)$. Prevalensi pada laki-laki $(0,42 \%)$ lebih tinggi dari perempuan $(0,35 \%)$, masyarakat perdesaan $(0,38 \%)$, tidak bersekolah $(0,57 \%)$, pekerjaan wiraswasta $(0,35 \%)$, petani $(0,46 \%)$ nelayan $(0,41 \%)$ buruh, supir, pembantu rumah tangga $(0,37 \%)$, dan provinsi dengan prevalensi tertinggi adalah Kalimantan Utara sebesar 0,64\%, diikuti Maluku Utara, Gorontalo dan Sulawesi Utara masing-masing sebesar $0,4 \%$.

Gagal ginjal disebabkan oleh fungsi organ ginjal yang mengalami penurunan sehingga tidak dapat menyaring pembuangan elektrolit tubuh. Selain itu organ ini juga tidak dapat menjaga keseimbangan antara cairan dan zat kimia tubuh seperti sodium dan kalium didalam darah atau produksi urine. Bisa jadi, ginjal seseorang menjadi tidak berfungsi secara mendadak, kondisi ini disebut acute renal failure. Biasanya penyakit tersebut 
dapat disembuhkan dengan obat-obatan dan dialisis atau cuci darah (Muhammad, 2017).

Hemodialisis atau cuci darah melalui mesin sudah dilakukan sejak tahun 1996-an. Hemodialisis di Indonesia, telah dijumpai pada beberapa rumah sakit pemerintah maupun swasta. Data statistik terkini menunjukkan bahwa setiap harinya tidak kurang dari 3700 orang menjalani cuci darah. Walaupun hemodialisis berfungsi serupa layaknya kerja ginjal, tindakan ini hanya mampu menggantikan sekitar 10\% kapasitas ginjal normal (Agoes dkk, 2018)

Hemodialisis dianjurkan dilakukan 2 kali seminggu, satu sesi hemodialisis memakan waktu sekitar 4 sampai 5 jam. Selama ginjal tidak berfungsi, selama itu pula hemodialisis harus dilakukan kecuali ginjal yang rusak diganti ginjal yang baru dari seorang pendonor. Pada proses hemodialisis, darah dari pembuluhnya disalurkan melalui selang kecil ke mesin yang disebut dializer. Setelah itu, darah yang telah bersih dikembalikan ke tubuh. Di dalam dializer, darah akan melewati suatu perangkat yang berfungsi sebagai saringan (Agoes dkk, 2018).

Ketergantungan pada mesin dialisis atau pasien yang menjalani hemodialisis seumur hidupnya dapat menyebabkan proses perubahan dalam kehidupan pasien yang menjalani hemodialisis dimana dapat menyebabkan salah satu terjadinya stres (Abbot C, 2010).

Stres adalah respon tubuh yang tidak spesifik terhadap setiap kebutuhan tubuh yang terganggu, suatu fenomena universal yang terjadi dalam kehidupan seharisehari dan tidak dapat dihindari setiap orang yang mengalaminya (Hawari,2018).

Berdasarkan hasil penelitian Rahayu dkk (2018), tentang hubungan frekuensi hemodialisis dengan tingkat stres pada pasien gagal ginjal yang menjalani hemodialisis menunjukkan bahwa mayoritas responden mengalami tingkat stres sedang sehingga disimpulkan terdapat hubungan yang siknifikan antara frekuensi hemodialisis pada pasien gagal ginjal kronik yang mengaami hemodialisis dengan nilai $\mathrm{p}$ value $0,041<0,05$.

Menurut penelitian Ina Ardila dan Dwi Retno Sulistyaningsih (2013), menunjukakan bahwa mayoritas respoden mengalami tingkat stres ringan sebanyak $(34,8 \%)$ sehingga disimpulkan ada hubungan antara tingkat stres dengan kulitas hidup pasien gagal ginjal kronik yang menjalani hemodialisis dengan p value 0,014 dan $\mathrm{r} 0,796$.

Berdasarkan penelian Astri Ipo dkk (2016), menunjukakan bahwa pasien yang melakukan hemodialisis dengan frekuensi $2 \mathrm{x}$ seminggu sebanyak $(77,5 \%)$ sehingga dapat disimpulkan bahwa terdapat hubungan yang bermakna antara frekuensi hemodialisis dengan kualitas hidup pasien yang menjalani hemodialisis dengan $p$ value 0,010 .

Menurut penelitian Wahyuni dkk (2018), didapatkan pasien yang menjalani hemodialisis kurang dari dua belas bulan sebanyak $(54,8 \%)$ dan empat diantaranya memiliki kualitas hidup yang baik dan tiga belas lainya memiliki kualitas hidup yang buruk sehingga disimpulkan bahwa terdapat hubungan yang bermakna antara lama menjalani hemodialisis dengan kualitas hidup pasien gagal ginjal kronik.
Hasil survei awal yang di lakukan peneliti pada tanggal 09 April 2019 di Rumah Sakit Royal Prima Medan di temukan bahwa penderita penyakit gagal ginjal kronik yang menjalani hemodialisis, didapatkan data sebanyak 70 orang pasien menjalani hemodialisis.

\section{METODE}

Jenis penelitian adalah deskriptif korelasi dengan desain cros sectional dimana variabel dependent dan independent diteliti secara bersamaan (Notoatmodjo, 2017).Penelitian ini bertujuan untuk mengetahui hubungan frekuensi hemodialisis dengan tingkat stress pada pasien gagal ginjal kronik yang menjalani hemodialisis di RSU Royal Prima Medan Tahun 2019. Teknik pengumpulan data dalam penelitian ini menggunakan data primer dan data sekunder. Data primer adalah data yang diperoleh langsung dari pasien ketika mengisi lembaran kuesioner stres (DASS-42) pada saat penelitian dilakukan. Data sekunder diperoleh dari rekam medis. Teknik pengambilan sampel menggunakan total sampling yaitu seluruh populasi di jadikan sampel (Jiwantoro, 2017)

\section{HASIL}

\section{Analisa Univariat}

Berdasarkan hasil penelitian yang dilakukan pada tanggal 08-09 Juli 2019 tentang hubungan frekuensi hemodialisis dengan tingkat stres pada pasien gagal ginjal kronik di RSU Royal Prima Medan Tahun 2019, maka diperoleh hasil sebagai berikut:

Tabel 3.1. Distribusi Frekuensi Hemodialisis Pasien Gagal Ginjal Kronik Yang Menjalani Hemodialisis di RSU Royal Prima Medan Tahun 2019.

\begin{tabular}{llll}
\hline No. & Variabel & Frekuensi & $\begin{array}{l}\text { Persentase } \\
(\mathbf{\%})\end{array}$ \\
\hline 1. & 2x seminggu & 48 & 68,6 \\
2. & 3x seminggu & 22 & 31,4 \\
\hline & Total & $\mathbf{7 0}$ & $\mathbf{1 0 0}$ \\
\hline
\end{tabular}

Berdasarkan tabel 3.1 diatas diketahui bahwa frekuensi hemodialisis pasien gagal ginjal kronik di peroleh bahwa mayoritas frekuensi $2 \mathrm{x}$ seminggu sebanyak 48 responden $(31,4 \%)$, dan minoritas yang ferekuensi hemodialisis $3 \mathrm{x}$ seminggu sebanyak 22 responden di RSU Royal Prima Medan Tahun 2019.

Tabel 3.2. Distribusi Tingkat Stres Pasien Gagal Ginjal Kronik Yang Menjalani Hemodialisis di RSU Royal Prima Medan Tahun 2019.

\begin{tabular}{llll}
\hline No. & $\begin{array}{l}\text { Tingkat } \\
\text { stress }\end{array}$ & Frekuensi & $\begin{array}{l}\text { Persentase } \\
(\boldsymbol{\%})\end{array}$ \\
\hline 1. & Normal & 12 & 17,1 \\
2. & Ringan & 27 & 38,6 \\
3. & Sedang & 20 & 28,6 \\
4. & Berat & 11 & 15,7 \\
\hline & Total & $\mathbf{7 0}$ & $\mathbf{1 0 0}$ \\
\hline
\end{tabular}


Berdasarkan tabel 3.2 diatas diketahui bahwa tingkat stres pasien gagal ginjal kronik diperoleh bahwa mayoritas mengalami tingkat stres ringan sebanyak 27 orang $(38,6 \%)$ dan minoritas yang tingkat stres sedang sebanyak 20 orang $(28,6 \%)$ dan yang tingkat stress normal sebanyak 12 orang $(17,1 \%)$, sedangkan stres berat minoritas sebanyak 11 responden $(15,7)$ di RSU Royal Prima Medan.

\section{Analisa Bivariat}

Bardasarkan hasil penelitian yang dilakukan pada Tanggal 08-09 Juli Tahun 2019 tentang hubungan frekuensi hemodialisis dengan tingkat stres pada pasien gagal ginjal kronik di RSU Royal Prima Medan Tahun 2019.

Tabel 3.3. Hubungan Frekuensi Hemodialisis denganTingkat Stres Pada Pasien Gagal Ginjal Kronik yang menjalani hemodialisis di RSU Royal Prima Medan Tahun 2019.

\begin{tabular}{|c|c|c|c|c|c|c|c|c|c|}
\hline \multicolumn{10}{|c|}{ Tingkat stress } \\
\hline \multirow{2}{*}{$\begin{array}{l}\text { Frekuensi } \\
\text { hemodialisis } \\
p=\text { Value }\end{array}$} & \multicolumn{2}{|c|}{ Normal } & \multicolumn{2}{|c|}{ Ringan } & \multicolumn{2}{|c|}{ Sedang } & Berat & & \\
\hline & $\mathbf{f}$ & $\%$ & f & $\%$ & f & $\%$ & f & $\%$ & \\
\hline $2 x$ seminggu & 8 & 11,4 & 12 & 17,2 & 17 & 24,3 & 11 & 15,7 & 0,002 \\
\hline $3 x$ seminggu & 4 & 5,7 & 15 & 21,4 & 3 & 4,3 & 0 & 0 & \\
\hline Total & 12 & 17,1 & 27 & 38,6 & 20 & 28,6 & 11 & 15.7 & \\
\hline
\end{tabular}

Dari tabel 3.3 di atas menunjukan bahwa pasien dengan frekuensi hemodialisis $2 \mathrm{x}$ seminggu mayoritas mengalami stres sedang sebanyak 17 orang $(24,3 \%)$ dan minoritas stres normal sebanyak 8 orang $(11,4 \%)$, sedangkan frekuensi hemodialisis yang $3 \mathrm{x}$ seminggu mayoritas mengalami stres ringan sebanyak 15 orang $(21,4 \%)$ dan minoritas mengalami stres sedang sebanyak 3 orang $(4,3 \%)$.

Berdasarkan hasil perhitungan uji chi-square, hubungan frekuensi hemodialisis dengan tingkat stres pada pasien gagal ginjal kronik yang menjalani hemodialisis di RSU Royal Prima Medan Tahun 2019 didapatkan nilai $\mathrm{p}$ value $=0,002 \leq 0,05$ maka dapat disimpulkan bahwa ada hubungan yang signifikan antara frekuensi hemodialisis dengan tingkat stres pada pasien gagal ginjal kronik di RSU Royal Prima Medan Tahun 2019.

\section{PEMBAHASAN}

\section{Analisa Univariat}

Frekuensi Hemodialisis pada Pasien Gagal Ginjal Kronik di Instalasi Hemodialisa di RSU Royal Prima Medan.

Berdasarkan hasil penelitian diperoleh bahwa mayoritas pasien menjalani frekuensi hemodialisis $2 \mathrm{x}$ seminggu sebanyak 48 orang $(68,6 \%)$. hal ini dikarenakan pasien gagal ginjal kronik yang menjalani hemodialisis fungsi ginjalnya sudah mengalami kerusakan dan penurunan fungsi ginjal stadium akhir, sehingga pasien tidak dapat lagi bertahan hidup tanpa melakukan hemodialisis $2 \mathrm{x}$ seminggu. Semakin menurun fungsi ginjal maka semakin banyak pula sampah sisa hasil metabolisme yang tidak bisa dibuang yang menumpuk dalam tubuh dan membahayakan, salah satu terapinya adalah hemodialisis.

Tingkat Stres Pada Pasien Gagal Ginjal Kronik Yang Menjalani Hemodialisis di RSU Royal Prima Medan Tahun 2019

berdasarkan hasil penelitian terhadap 70 responden dapat dilihat distribusi frekuensi responden berdasarkan tingkatan stres yaitu stres ringan sebanyak 27 $(38,6 \%)$,stres sedang sebanyak $20(28,6)$ dan stres berat sebanyak 11 orang $(15,7 \%)$.

Dari hasil penelitian di peroleh bahwa mayoritas 27 orang $(44,3 \%)$ pasien mengalami stress ringan karena menjalani hemodialisis, hal ini dikarenakan pasien gagal ginjal kronik yang menjalani hemodialisis sudah terlalu lama menjalani hemodialisis sehingga sebagian pasien sudah merasa terbiasa dengan segala keadaan yang sedang dijalaninya saat ini dalam dirinya,meskipun banyak masalah yang dihadapi tetapi pasien selalu tetap berpikiran positif sehingga tidak mengganggu system psikologis pasien tersebut.

Berdasarkan penelitian diperoleh data 11 orang $(15,7)$ pasien mengalami stress berat, hal ini dikarenakan pasien merasa cemas karena penyakit gagal ginjal kronik yang tidak bisa disembuhkan, dan belum berbagai komplikasi yang dialami pasien gagal ginjal kronis baik masalah fisik dan mental, pasien memang merasa sulit dalam menghadapi dan menjalani proses hemodialisis yang dilakukan sebanyak 2x seminggu sampai 3x seminggu seumur hidup, belum lagi masalah dalam segi biaya pada saat menjalani hemodialisis sehingga pasien mengalami stres.

\section{Analisa Bivariat}

Hubungan Frekuensi Hemodialisis Dengan Tingkat Stress pada Pasien Gagal Ginjal Kronik Yang Menjalani Hemodialisis di RSU Royal Prima Medan.

Pada hasil penelitian yang dilakukan diperoleh data mayoritas 20 orang $(28,6 \%)$ mengalami stres sedang hal ini dikarenakan pasien gagal ginjal kronik sudah dapat menyesuaikan diri dengan kodisi yang sedang dialaminya dan pasien juga sudah dapat menerima penyakit yang dideritanya. Pasien juga sudah lebih sabar mengadapi penyakit serta cobaan yang menimpa sehingga dengan hal ini pasien tidak merasa stres berat dan tidak mengganggu mental pasien.

Berdasarkan hasil penelitian yang dilakukan juga didapatkan data 12 orang $(17,1 \%)$ pasien yang mengalami stres normal hal ini dikarenakan pasien sudah bisa menerima dan pasien sudah pasrah dengan apa yang terjadi dalam hidupnya meskipun di hari-hari yang mereka jalani banyak masalah tetapi mereka selalu kuat dan semangat melewati berbagai rintangan dan cobaan.

Menurut penelitian Dessy Hadrianti dkk (2018), mengatakan bahwa Respon awal yang muncul ketika harus menjalani hemodialisis adalah menangis, kaget, takut dan menolak. Respon dan sikap selama menjalani hemodialisis adalah menyangkal, menerima, ikhlas, sabar, pasrah dan bersyukur. 


\section{KESIMPULAN}

Berdasarkan hasil penelitian mengenai Hubungan frekuensi hemodialisis dengan tingkat stres pada pasien gagal ginjal kronis yang menjalani hemodialisis di RSU Royal Prima Medan Tahun 2019, maka ditarik kesimpulan sebagai berikut:

Berdasarkan frekuensi hemodialisis mayoritas responden lebih sering mengikuti hemodialisis 2 kali seminggu dan berdasarkaan tingkat stres mayoritas responden mengalami stres ringan.Ada hubungan frekuensi hemodialisis dengan tingkat stres pada pasien gagal ginjal kronis yang menjalani hemodialisis di RSU Royal Prima Medan Tahun 2019.

\section{SARAN}

\section{Bagi Responden}

Diharapkan responden dapat menerima kedaannya dan dapat menjalani proses hemodialisis tanpa mengganggu kesehatan dan agar pasien mampu untuk menghindari dirinya dari keadaan stres akibat dari penyakitnya.

\section{Bagi Tempat Peneliti}

Diharapkan dapat meningkatkan pelayanan kesehatan serta membantu mensosialisasikan pendidikan kesehatan tentang adanya hubungan frekuensi hemodialisis dengan tingkat stres pada pasien gagal ginjal kronis hemodialisis yang menjalani hemodialisis di RSU Royal Prima Medan Tahun 2019.

\section{DAFTAR PUSTAKA}

Abbot, K. C., (2010). Body mass index, dialyis modality and survival: analysis of the united state renal data system dialysis morbidity and mortality wave II study. Journal kidney international.65.597-605. Diaksesdarihttps://reader.elsevier.com/reader/sd/p ii/S008525381549742X?token=4613A916D4104 E42E9EA67801F5F01C275746C8B1B5AA57F 6A8356AA67548FC4C94B88FDBEC3E45DED CA3CC716974DA4

Agoes, A., Agoes, A., \& Agoes, A. (2018). Penyakit di usia tua. Jakarta: EGC.

Astri, I., Tuti, A., \& Marta, S. (2016). Hubungan jenis kelamin dan frekuensi hemodialisa dengan kualitas hidup pasien gagal ginjal kronikyang menjalani hemodialisa di RSU Daerah Raden Mattaher Jambi. Jurnal akademi baiturrahim 5 (2). Diakses dari http://jab.stikba.ac.id/index.php/ jab/article/view/7

Dessy,H., Dyah, Y.,\& Ruslinawati. (2018). Pengalaman menjalani hemodialisis pada pasien gagal ginjal kronik di RS Banjarmasin. Jurnal kesehatan. 8(2). Diakses darihttp://download.garuda.ristekdikti.go.id/articl e.php?article $=9$
70031\&val=14928\&title=Chronic\%20Kidney $\% 2$ 0Failure\%20Patients'Experiences\%20of\%20He modialysis\%20at $\%$

Dinas Kesehatan Provinsi Sumatera Utara. (2014). Rekapitulasi kasus penyakit tidak menular. Diakses dari https://www.google.com/search?q=data+penyakit +tidak+menular+di+sumatera+utara+2014\&rlz= 1C1GGRV_enID844ID844\&oq=data+penyakit+ tidak+menular+di+sumatera+utara+2014\&aqs $=c$ hrome..69i57.48113j0j7\&sourceid=chrome\&ie= UTF-8

Fitri, R., Rafika, R., \& Topan, F. (2018). Hubungan frekuensi hemodialisis dengan tingkat stres pada pasien gagal ginjal kronik yang menjalani hemodialisis. Jurnal keperawatan silampari, 1(2), 139-153. Diakses dari https://www.neliti.com/id/publications/256091/hu bungan-frekuensi-hemodialisis-dengan-tingkatstres-pada-pasien-gagal-ginjal-kronik.

Hawari D. (2008). Manajemen Stres, Cemas Dan Adaptasi. Jakarta : Dua As As

Ina, A., \& Dwi, R. S. (2013). Hubungan tingkat stres dengan kualitas hidup psien penyakit gagal ginjal kronik yang menjalani hemodialisa di RSU Daerah Kota Semarang. Jurnal ilmu keperwatan dan kebidanan,1(10), 569-637.Diaksesdari http://ejournal.stikestelo gorejo.ac.id/index.php/jikk/article/ view/317.Indonesia Renal Registry (IRR). (2017). Report of indonesian renal registry. 7-8. Diakses dari

https://www.indonesianrenalregistry.org/data/IR R\%202017\%20.pdf

Infodatin, Pusat Data dan Informasi Kementerian Kesehatan RI. (2017). Situasi penyakit ginjal kronis. 1-2. Diaksesdari http://www.depkes.go.id/ download.php?file=download/pusdatin/infodatin/ infodatin\%20ginjal\%202017.pdf.

Jiwantoro, YA. (2017). Riset keperawatan analisis data statistik menggunakan SPSS. Jakarta: Mitra Wacana Media

Muhammad, A. (2017). Serba-serbi gagal ginjal. Yogyakarta: DIVA Press.

Notoatmodjo, S. (2017). Metode penelitian kesehatan. Jakarta: Rineka Cipta.

Riset Kesehatan Dasar (RISKESDAS). (2018). Hasil utama riskesdas 2018. 5962.Diaksespadahttp://www.depkes.go.id/resour ces/download/info-terkini/ hasil-riskesdas2018.pdf.

Suharyanto, T., \& Madjid, A. (2009). Asuhan keperawatan pada klien dengan gangguan system perkemihan. Jakarta: TIM. 


\title{
PENGARUH MENGKONSUMSI REBUSAN DAUN SIRSAK TERHADAP PENURUNAN NYERI PADA PENDERITA ASAM URAT DI PANTI JOMPO YAYASAN GUNA BUDI BAKTI MEDAN TAHUN 2019
}

\author{
Henrikus Halawa ${ }^{1}$, Karmila Br Kaban ${ }^{2}$, Handayani Munthe ${ }^{3}$, Nikita Asri Mendrofa ${ }^{4}$, \\ Princess Meilyn Simorangkir ${ }^{5}$. \\ Program Studi S1-Keperawatan Fakultas Keperawatan dan Kebidanan \\ Universitas Prima Indonesia Medan \\ henrichalawa@gmail.com
}

\begin{abstract}
Abstrak
Asam urat adalah zat hasil metabolisme purin dalam tubuh dalam kondisi normal Asam urat biasanya akan dikeluarkan oleh ginjal melalui urin. Namun dalam kondisi tertentu, ginjal tidak mampu mengeluarkan zat asam urat secara seimbang sehingga terjadi kelebihan dalam darah yang menimbulkan penumpukan kristal asam urat, yang akan memicu reaksi inflamasi yang menyebabkan terjadinya nyeri. Jenis terapi herbal yang dapat di gunakan dalam mengurangi nyeri pada penderita asam urat yaitu daun sirsak (Annona Muricata L). Tujuan penelitian ini bertujuan untuk mengetahui pengaruh mengkonsumsi rebusan daun sirsak terhadap penurunan nyeri pada penderita asam urat di Yayasan Guna Budi Bakti Medan. Jenis penelitian ini menggunakan desain pre-eksperimen dengan rancangan one group pre-test post-test design. Sampel diambil dengan menggunakan total sampling yaitu sebanyak 25 orang. Pengumpulan data menggunakan lembaran observasi. Analisa data menggunakan uji Wilcoxon sign rank test dengan signifikasi 0,05. Hasil penelitian uji Wilcoxon sign rank test pada hasil akhir di dapatkan nilai $\mathrm{p}=$ value $0,000<\alpha=0,05$ sehingga dapat diambil Kesimpulan bahwa adanya pengaruh mengkonsumsi rebusan daun sirsak terhadap penurunan nyeri pada penderita asam urat. Saran untuk peneliti selanjutnya dapat meneliti pengaruh mengkonsumsi rebusan daun sirsak pada penyakit lainnya seperti penyakit kanker.
\end{abstract}

Kata Kunci : asam urat; rebusan daun sirsak.

\section{PENDAHULUAN}

Usia harapan hidup dan status gizi masyarakat pada saat ini mengalami perubahan pola kebiasaan hidup termasuk pola makan. Hal ini berdampak pada perubahan penyakit yang diderita oleh masyarakat dari penyakit menular menjadi penyakit tidak menular. Perubahan pola penyakit ini berhubungan dengan pola makan, kebiasaan mengkonsumsi makanan yang mengandung karbohidrat, serat dan vitamin berubah menjadi pola makan yang banyak mengandung garam, lemak, bahan pengawet dan semua makanan yang mengandung purin. Pola makan seperti ini menyebabkan kadar asam urat dalam tubuh akan berlebih dan menimbulkan penumpukan kristal asam urat (tofus) di dalam jaringan ikat di seluruh tubuh yang akan memicu reaksi inflamasi yang menyebabkan terjadinya nyeri, dikenal dengan istilah penyakit asam urat (gout) (Ilkafah, 2017).

Asam urat adalah zat hasil metabolisme purin dalam tubuh dalam kondisi normal Asam urat biasanya akan dikeluarkan oleh ginjal melalui urin. Namun dalam kondisi tertentu, ginjal tidak mampu mengeluarkan zat asam urat secara seimbang sehingga terjadi kelebihan dalam darah kelebihan zat asam urat ini akhirnya menumpuk dan tertimbun pada persendian-persendian dan termasuk di ginjal itu sendiri (Pratiko, 2016). Faktor resiko yang menyebabkan terserang penyakit asam urat adalah suku dan bangsa, kegemukan, pola makan. Alkohol juga dapat menyebabkan asam urat, alkohol akan memicu pengeluaran cairan (urin) sehingga meningkatkan kadar asam urat di dalam darah sehingga asam urat tetap bertahan di dalam darah (Ardhila, 2013). Prevalensi penderita asam urat di dunia berdasarkan WHO di perkirakan mencapai 230 juta orang (Dwi Wibowo, dkk. 2017). Prevalensi penderita asam urat di Inggris diperkirakan memiliki prevalensi 1,4 \% $-7 \%$ dan prevalensi di Amerika menunjukkan dari tahun 1990 dan 1999 terdapat peningkatan dari 21/1000 menjadi 41/1000. Prevalensi penderita asam urat di Taiwan 2005-2008 mengalami peningkatan kejadian asam urat pada lansia sebesar $19,7 \%$ dan lansia pria $23,3 \%$.

Berdasarkan Riskesdas prevalensi penyakit sendi berdasarkan diagnosis pada penduduk umur $\geq 15$ tahun menurut provinsi dari tahun 2013-2018 di Indonesia pada tahun 2013 sebanyak 11,9 sedangkan pada tahun 2018 di Indonesia sebanyak 7,3. Prevalensi penyakit sendi pada umur $\geq 15$ tahun berdasarkan prevalensi dokter pada tahun 2018 sebanyak 1,2 pada umur 15-24 tahun sedangkan pada umur 75 tahun sebanyak 18,9 dan paling banyak diderita oleh perempuan sebanyak 8,5\% 
sedangkan pada laki-laki lebih sedikit sebanyak 6,1\%. Lalu di daerah perkotaan sebanyak 6,9\% sedangkan di daerah pedesaan sebanyak $7.8 \%$ (Riskesdas, 2018).

Prevalensi penyakit sendi berdasarkan diagnosis dokter pada penduduk umur $\geq 15$ tahun menurut karakteristik tahun 2018, tidak/belum pernah sekolah 13,7 $\%$ sedangkan tamatan D1/D2/D3 sebanyak 5,1\%. Berdasarkan pekerjaan, yang paling tinggi prevalensinya adalah petani sebanyak 9,90\%, sedangkan prevalensi paling rendah pada anak sekolahan sebanyak $1,10 \%$ (Riskesdas, 2018).

Pengobatan yang dilakukan untuk mengurangi nyeri dapat diakukan secara farmakologis dan non farmakologis. Penanganan farmakologis yaitu pemberian obat kelompok salisilat dan kelompok obat anti inflamasi nonsteroid, tetapi salah satu efek yang serius dari obat anti inflamasi nonsteroid adalah perdarahan saluran cerna. Sedangkan penanganan non farmakologis tidak mahal dan tidak memiliki efek yang berbahaya.

Dalam keperawatan terapi non farmakologi disebut keperawatan komplementer, Terapi komplementer merupakan terapi alamiah diantaranya adalah dengan terapi herbal. Jenis terapi herbal yang dapat di gunakan dalam mengurangi nyeri pada penderita asam urat yaitu daun sirsak (Annona Muricata L.) (Wirahmadi, 2013).

Pada daun dan buahnya mengandung senyawa fruktosa, lemak, protein, kalsium, fosfor, besi, vitamin, A dan vitamin B. Metabolit sekunder yang terkandung di dalamnya adalah senyawa golongan tanin, fitosterol (Sumantri, et all 2014). Senyawa yang paling penting adalah tannin, resin dan magostine yang mampu mengatasi nyeri sendi pada penyakit gout (Lina \& Juwita dalam Wirahmadi, 2013).

Penelitian ini bertujuan untuk Mengetahui gambaran skala nyeri penderita asam urat sebelum mengkonsumsi rebusan daun sirsak di Yayasan Guna Budi Bakti Medan tahun 2019. Mengetahui gambaran skala nyeri penderita asam urat setelah mengkonsumsi rebusan daun sirsak di Yayasan Guna Budi Bakti Medan tahun 2019. Mengetahui pengaruh mengkonsumsi rebusan daun sirsak terhadap penurunan nyeri pada penderita asam urat di Yayasan Guna Budi Bakti Medan tahun 2019. Serta diharapkan dapat dijadikan sebagai masukan pengetahuan serta intervensi keperawatan dan dapat diterapkan mengkonsumsi rebusan daun sirsak untuk penurunan nyeri pada penderita asam urat.

\section{METODE PENELITIAN}

Penelitian ini merupakan penelitian Preeksperimen maka peneliti menggunakan rancangan one group pre-test post-test design yaitu kelompok subyek di observasi sebelum dilakukan intervensi, kemudian di observasi lagi setelah dilakukan intervensi (Ilkafah,2017).

Lokasi penelitian Di Panti Jompo Yayasan Guna Budi Bakti Tahun 2019, Penelitian di lakukan pada tanggal 8-Juni-2019 s/d 14-Juni-2019. Populasi dalam penelitian adalah seluruh penderita asam urat yang tidak mengkonsumsi terapi farmakologi jenis obat anti inflamasi di Panti Jompo Yayasan Guna Budi Bakti tahun 2019 dengan jumlah 25 orang.
Sampel adalah bagian dari jumlah dan karakteristik yang di miliki oleh populasi tersebut" (Sugiyono,2010:81). Karena jumlah populasi kurang dari 30 orang maka, teknik pengambilan sampel pada penelitian ini dilakukan secara total sampling yaitu teknik penentuan sampel bila semua anggota populasi digunakan sebagai sampel (Sugiyono,2010:85). Jadi jumlah sampel pada penelitian sebanyak 25 orang.

Teknik pengumpulan data yang dilakukan dalam penelitian ini adalah dengan menggunakan lembaran observasi \& skala nyeri Visual Analog Scale (VAS).

Data dianalisis melalui analisis univariat dan analisa bivariat dilakukan untuk mengetahui pengararuh anatara varibel yang independen dengan varibel dependen dengan menggunakan uji Wilcoxon sign rank test dengan tingkat kepercayaan 95\%, Ha diterima jika nilai $\mathrm{p}<0,05$ berarti ada pengaruh antara kedua variabel yang diteliti, Ha diterima dan apabila $\mathrm{p}>0,05$ Ho diterima (Ha ditolak) maka diartikan tidak ada pengaruh.

\section{HASIL DAN PEMBAHASAN}

\section{A. Hasil Penelitian}

Tabel 1. Distribusi Responden Menurut Skala Nyeri Sebelum Mengkonsumsi Rebusan Daun Sirsak di Panti Jompo Yayasan Guna Budi Bakti Tahun 2019

\begin{tabular}{lll} 
Nyeri & Jumlah (n) & Persentase (\%) \\
Nyeri Ringan & 2 & 8 \\
Nyeri Sedang & 13 & 52 \\
Nyeri Berat & 10 & 40 \\
\hline Total & 25 & 100
\end{tabular}

Sumber : Data Primer, 2019

Tabel 2. Distribusi Responden Menurut Skala Nyeri Sesudah Mengkonsumsi Rebusan Daun Sirsak di Panti Jompo Yayasan Guna Budi Bakti Tahun 2019

\begin{tabular}{lll} 
Nyeri & Jumlah (n) & Persentase (\%) \\
Nyeri Ringan & 16 & 64 \\
Nyeri Sedang & 6 & 24 \\
Nyeri Berat & 3 & 12 \\
\hline Total & 25 & 100
\end{tabular}

Sumber : Data Primer, 2019

Tabel 3. Uji Normalitas Data Responden dan Pengaruh Pemberian Rebusan Daun Sirsak Pada Skala Nyeri Pada Responden di Panti Jompo Yayasan Guna Budi Bakti Tahun 2019

\begin{tabular}{lllll} 
Variabel & $\begin{array}{l}\text { Shapiro- } \\
\text { wilk } \\
\text { Sig }\end{array}$ & Variabel & $\begin{array}{l}\text { Mean } \\
\text { Rank }\end{array}$ & p-value \\
\hline Pre Test & 0,020 & $\begin{array}{l}\text { Skala } \\
\text { Nyeri }\end{array}$ & 12,50 & 0,000 \\
Post & 0,000 & & 0,00 & \\
Test & & & &
\end{tabular}

Sumber : Data Primer, 2019

\section{B. Pembahasan}

Pembahasan ini menjelaskan hasil penelitian mengenai pengaruh mengkonsumsi rebusan daun sirsak terhadap penurunan nyeri pada penderita asam urat di Panti Jompo Yayasan Guna Budi Bakti Tahun 2019 
dengan 25 responden sebagai sampel. Pada tabel 1 distribusi responden menurut skala nyeri sebelum mengkonsumsi rebusan daun sirsak di Panti Jompo Yayasan Guna Budi Bakti tahun 2019, dengan mayoritas responden memiliki skala nyeri sedang dengan persentase $52 \%$ (13 responden). Kemudian diikuti oleh responden dengan skala nyeri berat dengan persentase $40 \%$ (10 responden) dan responden dengan minoritas skala nyeri ringan dengan persentase $8 \%$ ( 2 responden).

Sama hal nya dengan penelitian yang dilakukan oleh Gerry, Muliyadi \& Kallo (2015) dengan judul Pengaruh Mengkonsumsi Rebusan Daun Sirsak Terhadap Penurunan Nyeri Pada Penderita Gout Artritis Di Wilayah Kerja Puskesmas Pineleng, menyatakan bahwa sebelum diberikan intervensi dilakukan pengukuran terlebih dahulu, dalam penelitian Gerry, Muliyadi \& Kallo (2015) responden paling banyak mengalami nyeri sedang.

Pada tabel 2 distribusi responden menurut skala nyeri setelah mengkonsumsi rebusan daun sirsak di Panti Jompo Yayasan Guna Budi Bakti tahun 2019, dengan mayoritas responden memiliki skala nyeri ringan dengan persentase $64 \%$ (16 responden). Kemudian diikuti oleh responden dengan skala nyeri sedang dengan persentase $24 \%$ ( 6 responden) dan responden dengan minoritas skala nyeri berat dengan persentase $12 \%$ ( 3 responden).

Hal ini menunjukan terjadinya penurunan skala nyeri pada responden setelah mengkonsumsi rebusan daun sirsak selama 7 hari berturut-turut, hal ini sama dengan hasil penelitian yang dilakukan oleh Gerry, Muliyadi \& Kallo (2015) pada kelompok intervensi yang miliki pengaruh penurunan skala nyeri dengan $p$ value $=0,004$, hal yang sama juga ditunjukan pada hasil penelitian yang dilakukan oleh Sumartyawati, Adawiyah \& Prasetia (2018) dengan melihat efektivitas pemberian daun sirsak pada lansia menyatakan bahwa ada penurunan kadar asam urat, penurunan kadar asam urat ini akan berdampak pada skala nyeri yang dialami oleh lansia.

Pada tabel 3 menunjukan hasil uji normalitas dengan menggunakan metode uji normalitas Shapiro-wilk data responden dimana distribusi data responden pada data pre-test memiliki nilai sig $0,020<0,05$, maka data tidak berdistribusi normal, begitu juga dengan data post-test memiliki nilai sig $0,000<0,05$, maka data tidak berdistribusi normal dengan hasil uji tersebut disimpulkan data tidak berdistribusi normal, sehingga analisa data yang digunakan dalam penelitian ini adalah uji Wilcoxon Signed Rank Tes. Hal yang sama juga dilakukan dalam penelitian Gerry, Muliyadi \& Kallo (2015) yang menggunakan uji Wilcoxon Signed Rank Test untuk mengetahui pengaruh mengkonsumsi rebusan daun sirsak terhadap penurunan nyeri pada penderita gout arthritis di wilayah kerja Puskesmas Pineleng.

Berdasarkan hasil uji Wilcoxon Signed Rank Tes data yang di gunakan adalah hasil pengukuran skala nyeri sebelum mengkonsumsi rebusan daun sirsak pada hari pertama penelitian dan hasil pengukuran skala nyeri sesudah mengkonsumsi rebusan daun sirsak pada hari terakhir penelitian dengan nilai Mean Rank pretestposttest sebesar 12,50-0,00 dengan $p$-value 0,000 .

Dengan data diatas dapat di simpulkan bahwa ada pengaruh mengkonsumsi rebusan daun sirsak terhadap penurunan nyeri pada penderita asam urat hal ini di tunjukan dengan $p$-value $0,000<0,05$ sehingga $\mathrm{Ha}$ di terima dan Ho ditolak.

Hasil penelitian ini sesuai dengan hasil penelitian yang di lakukan oleh Gerry, Muliyadi \& Kallo (2015) dengan judul pengaruh mengkonsumsi rebusan daun sirsak terhadap penurunan nyeri pada penderita gout artritis di wilayah kerja Puskesmas Pineleng, pada kelompok intervensi yang mengkonsumsi rebusan daun sirsak miliki pengaruh penurunan skala nyeri dengan hasil $p$ value $=0,004$.

Hasil penelitian Sumartyawati, Adawiyah \& Prasetia (2018) dengan melihat efektivitas pemberian daun sirsak pada lansia menyatakan bahwa ada penurunan kadar asam urat pada responden yang diberikan intervensi dengan mengkonsumsi rebusan daun sirsak, penurunan kadar asam urat ini akan berdampak pada skala nyeri yang dialami oleh lansia.

Berdasarkan hasil penelitian yang dilakukan oleh Apriana, Retnaingsih \& Supriyanto (2014) menyatakan hasil uji Paired t-test dapat diketahui hasil uji statistik p value 0,000 dengan taraf signifikasi 0,05 dapat disimpulkan bahwa ada pengaruh terhadap nyeri gout arthritis pada responden setelah diberikan intervensi berupa terapi herbal air rebusan daun sirsak.

Pemberian rebusan daun sirsak yang mengandung zat etanol yang berperan sebagai anti inflamasi hal ini sesuai dengan pernyataan Wijaya (2012) bahwa daun sirsak memiliki ekstrak etanol dan magostine yang berperan sebagai anti inflamasi dan mampu meredam nyeri pada penderita asam urat. Setelah diberikan intervensi mengkonsumsi rebusan daun sirsak responden mengalami penurunan skala nyeri. Mengkonsumsi Rebusan daun sirsak sebagai terapi komplementer sangatlah baik karena bahan yang di gunakan adalah bahan yang alami dan tidak memiliki efek samping, daun sirsak serta pengolahannya sangat untuk mudah dilakukan.

\section{KESIMPULAN DAN SARAN}

Berdasarkan hasil penelitian yang kami lakukan mengenai pengaruh mengkonsumsi rebusan daun sirsak terhadap penurunan nyeri pada penderita asam urat, maka didapat kesimpulan bahwa skala nyeri pada responden berdasarkan pengukuran sebelum mengkonsumsi rebusan daun sirsak memiliki skala nyeri dengan mayoritas responden pada kategori nyeri sedang. Hasil pengukuran setelah mengkonsumsi rebusan daun sirsak skala nyeri yang dialami responden berdasarkan pengukuran pada hari terakhir penelitian memiliki skala nyeri dengan mayoritas responden pada kategori nyeri ringan.

Dari data diatas dapat menunjukan bahwa ada pengaruh mengkonsumsi rebusan daun sirsak terhadap penurunan nyeri pada penderita asam urat di Yayasan Guna Budi Bakti tahun 2019.

Pengobatan atau terapi komplementer alternatif dengan mengkonsumsi rebusan daun sirsak dapat diterapkan dalam upaya menurunkan nyeri pada penderita asam urat di Yayasan Guna Budi Bakti, hal ini di sarankan kepada pegawai yang mendampingi para penderita asam urat di Yayasan Guna Budi Bakti supaya tetap menganjurkan penderita asam urat untuk mengkonsumsi rebusan daun sirsak untuk menurunkan nyeri yang dialami 
oleh penderita asam urat, serta kepada penderita asam urat supaya tetap untuk mengkonsumsi rebusan daun sirsak secara teratur supaya nyeri yang dialami berkurang.

Hendaknya peneliti selanjutnya dapat meneliti pengaruh mengkonsumsi rebusan daun sirsak pada penurunan nyeri pada kasus yang berbeda seperti nyeri pada penderita kanker.

\section{DAFTAR PUSTAKA}

Apriana. R, Retnaingsih. D \& Supriyanto. J. (2014). Pengaruh Rebusan Daun Sirsak Untuk Menurunkan Nyeri Gout Atrhitis Pada Lansia. Stikes Widya Husada Semarang.https://jurnal.unimus.ac.id/index.php/p sn12012010/article/download/2321/2297. Diakses tanggal 14 Juni 2019.

Ardhilla City, Oktaviani Noni, (2013). DIASKOL JANTROKE (Diabetes Millitus,Asam Urat, Kolesterol, Jantung, dan Stroke). IN AzNa Books. Yogyakarta.

Fatriyadi, J. \& Irfa, R. (2016). Studi Pustaka Khasiat Daun Sirsak (Annona Muricata L).Dalam Menurunkan Nyeri Pada Pasien Gout Arthritis. Jurnal Majority, 5 (3). 2337 - 3776

Gerry, K. F., Mulyadi., \& Kallo, V. (2015). pengaruh mengkonsumsi rebusan daun sirsak terhadap penurunan nyeri pada penderita Gout Arthritis di wilayah kerja puskesmas pineleng, eJurnal Keperawatan (e-Kp). 3(2)

Gustomi, M.P., \& Wahyuningsih, F. (2016). Pemberian Rebusan Daun Sirsak (Annona Muricata L). Menurunkan Nyeri Pada Penderita Gout Arthritis, Journals of Ners Community, 07 (02), 162-172.
Ilkafah. 2017. Efektivitas Daun Sirsak Dalam Menurunkan Nilai Asam Urat Dan Keluhan Nyeri Pada Penderita Gout Di Kelurahan Tamalanrea Makassar. Pharmacon Jurnal Ilmiah FarmasiUNSRAT, 6 (2), 2302-2493.

Ismanto, S.D., Eliyasmi, R \& Osman, D. (2014). Penambafian Ekstrak Daun Sirsak Terhadap Minuman Instan Dari Buah Sirsak (Annona muricata,L). Prosiding Seminar dan Lokakarya Nasional FKPT-TPI 2014

Sari, I.K., Simandalahi,T \& Morika, H.D. (2018). Pengaruh Jus Sirsak Terhadap Kadar Asam Urat Pada Penderita Artritis Gout. Jurnal kesehatan saintika. 2655-5840

Sugiyono. 2010 Metode Penelitian Pendidikan Pendekatan Kuantitatif, kualitatif, dan R\&D. Bandung: Alfabeta

Sumartyawati, N. M., Adawiyah, R., \& Prasetia, A. (2018). Efektifitas Pemberian Rebusan Daun Sirsak (Annona Muricata L).Dan Senam Tera Terhadap Perubahan Kadar Asam Urat Pada Lansia Dengan Gout Arthritis di BSLU Mandalika Provinsi NTB. Prima (jurnal ilmiah kesehatan).4(1).2477-0604.

Wijaya. M. (2012). Ekstraksi annonaceous acetogenin daun sirsak, annona muricata, sebagai senyawa bioaktif anti kanker. (Skripsi). Jakarta: Fakultas Kedokteran Universitas Indonesia. https://www.lib.ui.ac.id. diakses pada tanggal 16 Mei 2019

Wirahmadi, Komang. 2013. Pengaruh Pemberian Rebusan Daun Sirsak Terhadap Nyeri Pada Penderita Gout Di Kelurahan Genuk Barat Kecamatan Ungaran Kabupaten Semarang. 